Asian J. Med. Biol. Res. 2020, 6 (4), 738-745; doi: 10.3329/ajmbr.v6i4.51241

\author{
Asian Journal of \\ Medical and Biological Research \\ ISSN 2411-4472 (Print) 2412-5571 (Online) \\ www.ebupress.com/journal/ajmbr
}

\title{
Article \\ Physical disabilities and psychosocial status of the patients attending in a selected specialized hospital
}

\author{
Mst. Wazeda Begum ${ }^{1 *}$, Ashees Kumar Saha ${ }^{2}$, China Rani Mittra ${ }^{3}$, Sajeda Khatun ${ }^{4}$ and Khorshed Ali Miah ${ }^{5}$ \\ ${ }^{1}$ Lecturer, Dinajpur Nursing College, Dinajpur, Bangladesh \\ ${ }^{2}$ Nursing Officer, Upazila Health Complex, Bagha, Rajshahi, Bangladesh \\ ${ }^{3}$ Nursing Officer Upazilla Health Complex, Abhaynagar, Jashore, Bangladesh \\ ${ }^{4}$ Lecturer (deputed), Dinajpur Nursing College, Dinajpur, Bangladesh \\ ${ }^{5}$ Associate Professor, NIPSOM, Mohakhali, Dhaka-1212, Bangladesh
}

*Corresponding author: Mst. Wazeda Begum, Lecturer, Dinajpur Nursing College, Dinajpur, Bangladesh. Phone: +8801716213495; E-mail: wazeda.begum86@gmail.com

Received: 21 November 2020/Accepted: 17 December 2020/ Published: 31 December 2020

\begin{abstract}
This study was conducted at CRP Saver Dhaka, with a view to described the various factors that affect the physical disabilities and psychosocial status of the disabled patients, from January to December, 2015. The sample size was 150 and the data were collected by using purposive sampling technique with face-to-face interview. The study revealed that, counterpart (42\%). Rural area was found to have highest $(56.7 \%)$ of Physical disabilities than urban areas (43.3\%). Majority of respondents were come from middle and low income group. Neuromuscular disability found higher numbered (67\%) than that of musculo skeletal disability (33\%). Regarding reasons of disability stroke (25.3\%) was in highest position followed by fall from height (21.39\%), RTA (16\%) and occupational (5.30\%) respectively. Physical disability was one of the major causes of psychological problem. Physical disability hamper the social status, (10.7\%) of the respondents were lost their jobs due to disabilities. Study found the significance difference between the physical disabilities and interruption of community involvement $\left(\chi^{2}=34.162, \mathrm{p}=<0.05\right)$. Studies regarding psychosocial aspect among the disabled are rare. This study might be improving the understanding of psychosocial problem of the physical disabled and thereby strengthening the design of more effective identification, prevention and intervention strategies.
\end{abstract}

Keywords: motor; dexterity disabilities; musculo skeletal disability; osteogensis imperfect; muscular dystrophy; neuro musculo disability; cerebral palsy

\section{Introduction}

Approximately 650 million people in the world are disabled. Around 80 percent of these people live in developing countries (UN, 2011). According to the statistics of the World Health Organization (WHO), the number of people with a disability is estimated to be more than one billion. These numbers are increasing due to population growth, ageing process and medical advances (WHO, 2011).

According to the Physical Disability Council (2009), a physical disability can be defined as total or partial loss of a person's bodily functions (e.g. walking, gross or fine motor skills, bladder control etc.) and total or partial loss of a part of the body (e.g. a person with an amputation). Physical disabilities are also often referred to as motor disabilities. The disability can be the result of an accident or disease, but can also be congenital. Causes of physical disabilities include muscular dystrophy, multiple sclerosis, amputation or severe injury, spinal injuries. Physical disabilities can vary from temporary disabilities, such as broken limbs, to permanent disabilities (Altman, 2001). 
In recent year worldwide, the prevalence of disability is argued to be growing, with population ageing and increasing incidence of chronic health conditions. Approximately $16 \%$ of the adult population aged 18 and older worldwide is disabled, with noticeable differences between high income countries (12\%) and low income countries (18\%) (WHO and WB, 2011).

Today, the world population is over 7 billion. More than one billion people, or approximately 15 per cent of the world's population, live with some form of disability. $80 \%$ live in developing countries (UK, 2015). Bangladesh is a developing country located in South Asia and is home to approximately 160 million people. It is a country of widespread poverty, with $44.3 \%$ of the population living below the poverty line, inadequate health, education, and social security services, low employment and at high risk from natural disasters, particularly flooding. Estimates indicate that $10 \%$ of the population i.e. 16 million people are living with a disability and these are one of the most vulnerable groups as they receive little or no assistance (CDD, 2015).

The Rapid Assessment of Disability (RAD) survey was conducted a study at Bogra district in Bangladesh with 50 people aged 18 years and older in 2010. Of 1855 adults who participated in the study, $195(10.5 \%)$ had disability. Age and gender adjusted prevalence of disability in Bogra district was $8.9 \%$. The highest prevalence of functional limitation was related to psychological distress (4.7\%) followed by vision (4.4\%), and hearing (2.3\%) difficulties (Marella et al., 2015).

[Physically disabled persons are challenged to cope with a wide range of stressors in maintaining meaningful lives. Long life survive with disability is depends, in part, on psychological and social factors that promote effective coping with old and new demands. The objective of this study was thus to identify and summarize research on physical disabilities and psychosocial status among age 18 and above with disabilities. This research will be projected to assess the physical disabilities and psychosocial status. Many researchers were carried out their research on different aspect of disabilities, but current aspect is so far. Here researcher tried to review of different research of the social and psychological status of persons with physical disabilities and thereby strengthening the design of more effective identification, prevention and intervention strategies. It is said that Sustainable, equitable progress in the agreed global development agenda cannot be achieved without the inclusion of person with disabilities. If they are not include, progress in development will further there marginalization.

\section{Materials and Methods}

\subsection{Ethical consideration}

Ethical clearance was taken from ethical committee of NIPSOM prior to initiation of study. Verbal consent was taken from the respondent before interview by explaining the aims and objectives of the study, reason for invitation in this study. Full freedom of respondents to refuse and withdraw him/her from the study anytime during the study period was taken into consideration.

\subsection{Study design}

The study was a Cross- sectional study.

\subsection{Study population}

Patients who have disabilities with the age of 18 years and above attending in CRP Saver Dhaka.

\subsection{Study period}

The study was conducted from January to December, 2015.

a) Study place: The study was conducted in inpatient department and outpatient department of the Centre for the Rehabilitation of the Paralyzed (CRP) at Saver in Dhaka. It is specialized hospital for disable patient.

b) Sampling technique: Purposive sampling technique was used. Sample size 150 .

c) Inclusion criteria: Patient who admitted in inpatient department and attending in outpatient department and patient who provide consent to participate

d) Exclusion criteria: Patient who was below 18 years of age and who did not physically and mentally stable to engage themselves in this study.

\subsection{Tool of the study}

Semi- structured questionnaire were used as data collection tools. Barthel Index (customized) was used to assess the physical disability. Patient records were reviewed to collect the information regarding different types of disability. Before data collection, pre-testing of questionnaire and record review were done in CRP Mirpur 
Dhaka. Face to face interview and reviewing of patient records for collection of data. The interview was conducted after explained to each respondent and informed written consents were obtained from the respondents. Data were analyzed by Statistical Package for Social Science (SPSS) version 20.

\section{Results and Discussion}

As a cross sectional study data was collected at single point in time among 150 disabled patients.

Table 1. Demographic characteristics of the respondent $(n=150)$.

\begin{tabular}{|c|c|c|}
\hline Age category & Frequency & Percentages \\
\hline $18-27$ & 24 & 16.0 \\
\hline $28-37$ & 27 & 18.0 \\
\hline $38-47$ & 33 & 22.0 \\
\hline $48-57$ & 37 & 24.7 \\
\hline$>58$ & 29 & 19.3 \\
\hline Mean 44.43 & Std. \pm 15.33 & \\
\hline \multicolumn{3}{|l|}{ Gender } \\
\hline Male & 87 & 58 \\
\hline Female & 63 & 42 \\
\hline \multicolumn{3}{|l|}{ Marital status } \\
\hline Married & 132 & 88.0 \\
\hline Unmarried & 15 & 10.0 \\
\hline Divorce & 2 & 1.3 \\
\hline Widow & 1 & 0.7 \\
\hline \multicolumn{3}{|l|}{ Level of education } \\
\hline Graduation \& above & 31 & 20.7 \\
\hline SSC\&HSC & 39 & 26 \\
\hline Secondary education & 28 & 18.6 \\
\hline Primary education & 31 & 20.7 \\
\hline No education & 21 & 14 \\
\hline \multicolumn{3}{|l|}{ Occupation } \\
\hline Service & 37 & 24.7 \\
\hline Business & 24 & 16.0 \\
\hline Housewife & 52 & 34.7 \\
\hline Agriculture & 17 & 11.3 \\
\hline Day labor & 8 & 5.3 \\
\hline Student & 7 & 4.7 \\
\hline Others & 5 & 3.3 \\
\hline \multicolumn{3}{|c|}{ Earning member of the family } \\
\hline 1 & 86 & 57.3 \\
\hline 2 & 51 & 34.0 \\
\hline 3 & 10 & 6.7 \\
\hline 4 & 2 & 1.3 \\
\hline 5 & 1 & 0.7 \\
\hline \multicolumn{3}{|c|}{ Average monthly income } \\
\hline Upto 10,000 & 39 & 26.0 \\
\hline $10,001-20,000$ & 66 & 44.0 \\
\hline $20,001-30,000$ & 23 & 15.3 \\
\hline$>30,000$ & 22 & 14.7 \\
\hline \multicolumn{3}{|l|}{ Area of residence } \\
\hline Rural area & 85 & 56.7 \\
\hline Urban area & 65 & 43.3 \\
\hline Total & 150 & 100 \\
\hline
\end{tabular}

Table 1 shows that, highest number 37 (24.7\%) of the respondents were found to age group 48-57 years and lowest number $24(16 \%)$ of the respondents found to age group 18-27 years. Mean \pm STD was $44.43 \pm 15.33$ years respectively and from them $87(58 \%)$ were male and $63(42 \%)$ were female. Majority of the respondents 132 $(88 \%)$ was married and lowest number of respondent $1(0.7 \%)$ was widow, rest $15(10 \%)$ and $2(1.3 \%)$ was 
unmarried and divorce respectively. Out of 150 respondents, 39 (26\%) was SSC and HSC passed, no education was $21(14 \%)$, primary education, graduation \& above shown same $31(20.70 \%)$, rest secondary education was $28(18.70 \%)$ of the respondents. Most of the respondents $52(43.7 \%)$ were housewife and lowest $5(3.3 \%)$ others. It shown $37(24.7 \%), 24(16 \%), 17(11.3 \%)$ respondents were service, business, agriculture and day labor respectively. Here, $86(57.3 \%)$ of the respondent's family had 1 earning person, 51 (34\%) respondents had 2 earning person rest $10(6.7 \%), 2(1.3 \%)$ and $1(0.7 \%)$ respondents family had 3,4 and 5 earning person respectively. Among the respondents, highest monthly family income 66(44\%) were found to Tk. 10001 20000 .Very few family income $22(14.7 \%)$ found to $>30000$. Rest $39(26 \%)$ and $23(15.30 \%)$ family income were found up to 10000 and 20001-30000 Tk. respectively. Among the respondents, 85 (56.7\%) was lived in rural area and $65(43.3 \%)$ of the respondents lived in urban area.

Table 2. Distribution of the respondents according to Physical Disability related information $(n=150)$.

\begin{tabular}{|l|l|l|}
\hline Reason of disabilities & Frequency & Percentage \\
\hline Stroke & 38 & 25.30 \\
\hline Chronic diseases & 1 & 0.7 \\
\hline Chronic pain & 8 & 5.3 \\
\hline RTA & 23 & 16 \\
\hline Fall from height & 31 & 21.3 \\
\hline Fighting & 7 & 4 \\
\hline Joint and bone disease & 22 & 14.1 \\
\hline Occupational & 8 & 5.3 \\
\hline Others & 12 & 8 \\
\hline Types of paralysis & \multicolumn{2}{|l|}{} \\
\hline Monoplegia & 33 & 22.0 \\
\hline Hemiplegia & 40 & 26.7 \\
\hline Paraplegia & 45 & 30.0 \\
\hline Tetraplegia & 17 & 11.3 \\
\hline No paralysis & 15 & 10.0 \\
\hline Severity of physical disability & \multicolumn{2}{|l|}{} \\
\hline Mild & 51 & 34.0 \\
\hline Moderate & 67 & 44.7 \\
\hline Severe & 32 & 21.3 \\
\hline Total & $\mathbf{1 5 0}$ & $\mathbf{1 0 0 . 0}$ \\
\hline
\end{tabular}

Table 2 shows that, highest numbers of respondent's $38(25.30 \%)$ reason of disability was stroke. Lowest $1(0.7 \%)$ reson of disability was chronic disease. $31(21.3 \%)$ respondent's reason of disability was fall from height, $22(14.1 \%)$ reason of disability was joint and bone disease, $12(8 \%)$ respondent's reason of disability was others and 46(30.6\%) respondent's reason of disability was Chronic pain, RTA, Fighting and Occupational respectively. Among the respondents, types of disability found paraplegia, 45(30\%) of the respondents, hemiplegia $40(26.7 \%)$, monoplegia 33(22\%), tetraplegia $17(11.3 \%)$ of the respondents, rest $15(10 \%)$ of the respondents had no paralysis. Here we found that, among the respondents, severely physical disabled were found $32(21.3 \%)$ of the respondents, moderately disabled were 67(44.7\%) and rest 51(34.0\%) were mildly physical disabled.

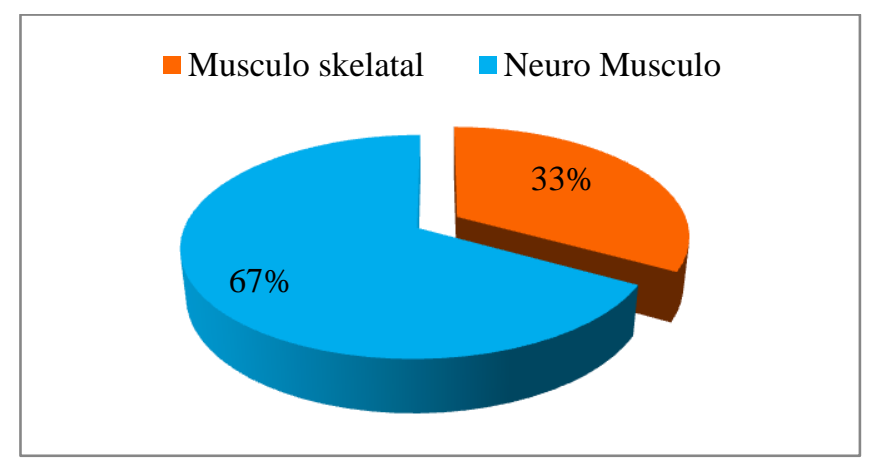

Figure 1. Distribution of the respondents by types of physical disabilities $(n=150)$. 
This study found that out of 150 respondents $67 \%$ had Musculo Skeletal disability, and 33\% had neuro musculo disability (Figure 1).

Table 3. Distribution of the respondents by inability of motor functions $(n=150)$.

\begin{tabular}{|c|c|c|}
\hline Ability to feed & Frequency & Percentage \\
\hline Unable & 17 & 11.3 \\
\hline Need help & 51 & 34.0 \\
\hline Able & 82 & 54.7 \\
\hline \multicolumn{3}{|c|}{ Ability to wear dress } \\
\hline Unable & 11 & 7.3 \\
\hline Need help & 89 & 59.3 \\
\hline Able & 50 & 33.3 \\
\hline \multicolumn{3}{|c|}{ Ability to use toilet } \\
\hline Unable & 12 & 8.0 \\
\hline Need help & 99 & 66.0 \\
\hline Able & 39 & 26.0 \\
\hline \multicolumn{3}{|c|}{ Ability to take bath } \\
\hline Unable & 37 & 24.7 \\
\hline Need help & 79 & 52.7 \\
\hline Able & 34 & 22.7 \\
\hline \multicolumn{3}{|c|}{ Ability to get into bed } \\
\hline Unable & 16 & 10.7 \\
\hline Need help & 99 & 66.0 \\
\hline Able & 35 & 23.3 \\
\hline \multicolumn{3}{|c|}{ Ability to walk outdoor in the street } \\
\hline Unable & 69 & 46.0 \\
\hline Need help & 59 & 39.3 \\
\hline Able & 22 & 14.7 \\
\hline \multicolumn{3}{|c|}{ Ability to walk stair } \\
\hline Unable & 70 & 46.7 \\
\hline Need help & 60 & 40.0 \\
\hline Able & 20 & 13.3 \\
\hline \multicolumn{3}{|c|}{ Ability to use wheelchair } \\
\hline Unable & 15 & 10.0 \\
\hline Need help & 73 & 48.7 \\
\hline Able & 62 & 41.3 \\
\hline Total & 150 & 100.0 \\
\hline
\end{tabular}

Table 3 shows that 17 (11.3\%) respondents was unable to feed whereas 51 (34\%) and $82(54.7 \%)$ was need help and able to feed respectively. Among 150 respondents, 11 (7.3\%) respondents showed unable to wear dress, 89 (59.3\%) respondents need help to wear dress and 50 (33.3\%) respondents were able to wear dress. Here, only 12 $(8 \%)$ were unable to use toilet, $99(66 \%)$ were need help and $39(26 \%)$ respondents were able to use toilet. Out of 150 respondents, 37 (24.7\%) was unable to take bath, 79 (52.7\%) need help and $34(22.7 \%)$ was able to take bath. Here we found that, $16(10.7 \%)$ respondents were unable to get into bed, 99 (66\%) need help and 35 $(23.3 \%)$ respondents were able to get into bed. It is seen that out of 150 respondents, 69 (46\%) was unable to walk outdoor in the street, $59(39.3 \%)$ was need help and $22(14.7 \%)$ was able to walk outdoor in the street. This study revealed that highest number $70(46.7 \%)$ was unable to walk stair lowest number $20(13.3 \%)$ able to walk stair and rest $60(40 \%)$ respondents need help to walk stair. Lowest number $15(10 \%)$ respondents was unable to use wheelchair and the highest number $73(48.7 \%)$ respondents was need help to use wheel chair, other 62 (41.3\%) respondents able to use wheelchair. 


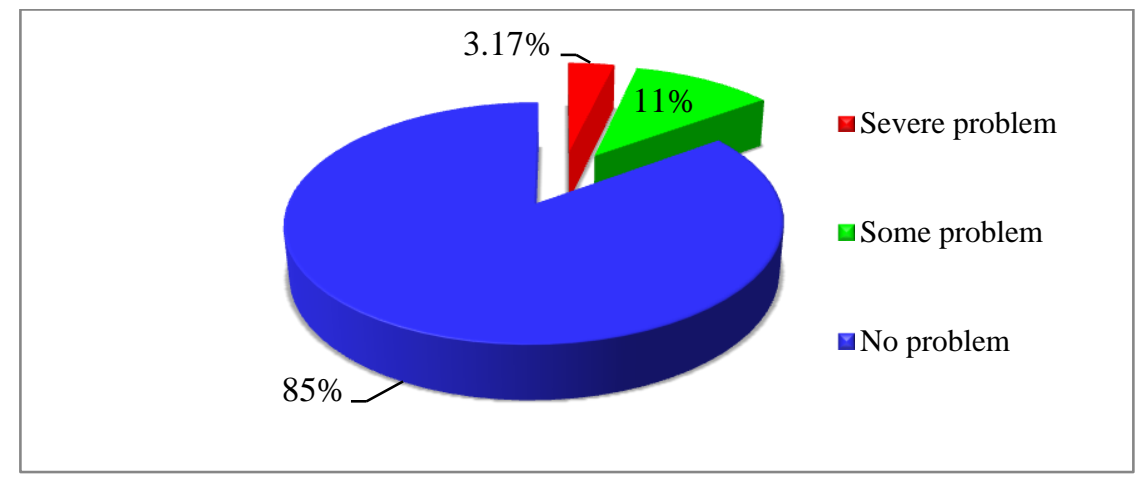

Figure 2. Distribution of the respondents by inability of sensory function $(n=150)$.

Figure 2 shows that out of 150 respondents, only $3.17 \%$ respondents had severe sensory problem and $11.33 \%$ respondents had some sensory problem rest $85.50 \%$ respondents had no sensory problem.

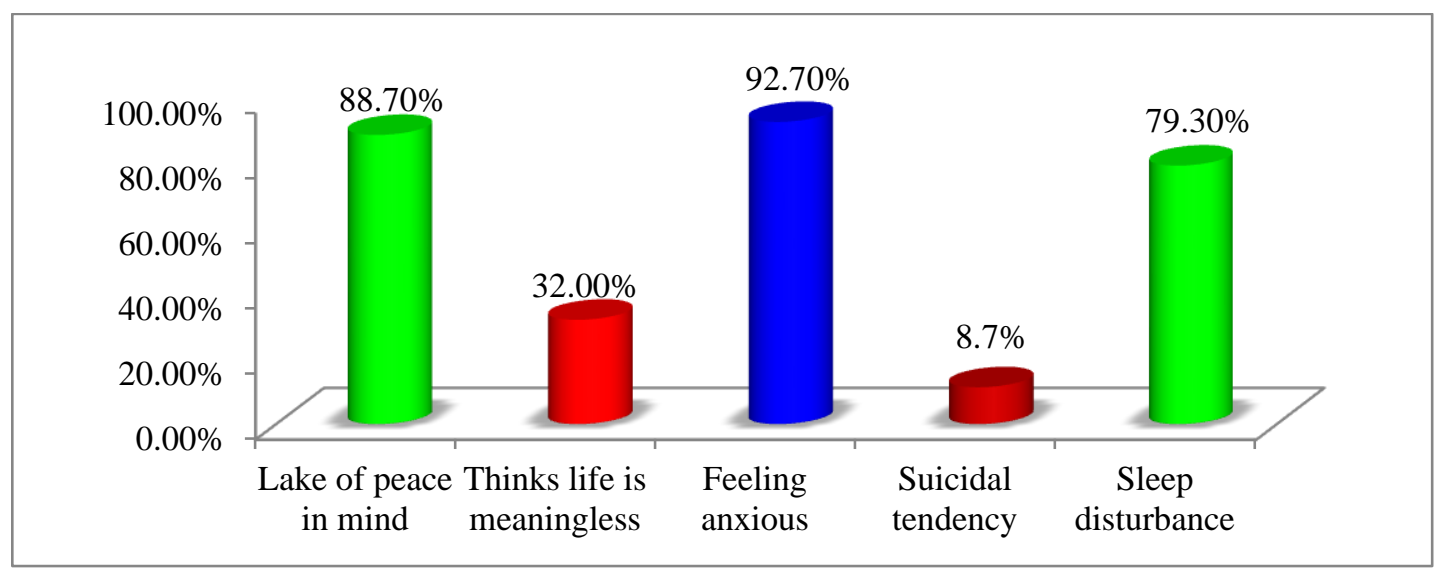

Figure 3. Distribution of the respondents by severe psychological problem.

Figure 3 revealed that highest number $(92.70 \%)$ of the respondents was feeling anxious, lowest number $(8.7 \%)$ had suicidal tendency, rest (88.70\%), (79.30\%) and (32\%) had lack of peace in mind, sleep disturbance and think life is meaningless respectively.

Table 4. Distribution of the respondent by their Social information $(n=150)$.

\begin{tabular}{|c|c|c|c|}
\hline Loss of working time (in month) & \multicolumn{2}{|l|}{ Frequency } & Percentage \\
\hline $1-20$ & \multicolumn{2}{|l|}{113} & 90.4 \\
\hline $21-40$ & \multicolumn{2}{|l|}{10} & 8.0 \\
\hline $41-60$ & \multicolumn{2}{|l|}{2} & 1.6 \\
\hline \multicolumn{4}{|l|}{ Loss of job } \\
\hline Yes & \multicolumn{2}{|l|}{16} & 10.7 \\
\hline Uncertain & \multicolumn{2}{|l|}{1} & 0.7 \\
\hline No & \multicolumn{2}{|l|}{133} & 88.7 \\
\hline Social Factors & Yes f $(\%)$ & No $f(\%)$ & Uncertain f (\%) \\
\hline Community involvement interrupted & $127(84.7)$ & $23(15.3)$ & $-\overline{---}$ \\
\hline Deprived from visit of neighbour & $106(70.7)$ & $43(28.7)$ & $1(0.7)$ \\
\hline Deprived from visit of relatives & $70(46.7)$ & $75(50)$ & $5(3.3)$ \\
\hline Deprived from receive care of family & $22(14.7)$ & $128(85.3)$ & ---- \\
\hline
\end{tabular}

Table 4 shows that, 113(90.4\%) of the respondents were found to loss of working times 1-20 months, lowest number 2(1.6\%) were found to 41-60 months, rest 10(8.0\%) of the respondents were found to loss of working times 21-40 months. Among 150 respondents 16(10.7\%) was lost their jobs due to disabilities, $1(0.7 \%)$ was uncertain, other $133(88.7 \%)$ of the respondents didn't lose their job. Highest number $127(84.7 \%)$ of the respondents' community involvement was interrupted and lowest $23(15.3 \%)$ of the respondents' community 
involvement not interrupted. Deprived from visit of neighbor was 106(70.7\%), uncertain 1(0.7\%), no deprive from visit of neighbor was $43(28.7 \%)$. Deprived from visit of relatives and deprived from receive care of family was $70(46.7 \%)$ and $22(14.7 \%)$ respectively.

Table 5. Difference between severity of physical disability and interruption of community involvement.

\begin{tabular}{|l|l|l|l|}
\hline \multirow{2}{*}{$\begin{array}{l}\text { Severity of physical } \\
\text { disability }\end{array}$} & \multicolumn{2}{|l|}{ Community involvement interrupted } & \multirow{2}{*}{ Total } \\
\hline Mild & Yes & No & \\
\hline Moderate & $31(60.8 \%)$ & $20(39.2 \%)$ & $51(100.0 \%)$ \\
\hline Severe & $83(97.6 \%)$ & $2(2.4 \%)$ & $85(100.0 \%)$ \\
\hline Total & $13(92.9 \%)$ & $1(7.1 \%)$ & $14(100.0 \%)$ \\
\hline
\end{tabular}

$\mathrm{df}=2, \chi^{2}=34.162, \mathrm{p}=0.001$

Majority $13(92.9 \%)$ of the respondents among the severely disabled were found that their community involvement were interrupted, on the other hand $31(60.8 \%)$ of the respondents among the mildly disabled found that their community involvement were interrupted. This difference between physical disabilities and community involvement was found statistically significance.

\section{Discussion}

The study was conducted to assess the physical disabilities and psychosocial status of the patients attending at Centre for the Rehabilitation of the Paralyzed (CRP) Saver Dhaka. In Bangladesh data regarding physical disabilities and psychosocial status are very limited. The outcomes of the study are discussed below:

In this study, highest number 37 (24.7\%) of the respondents were found to age group 48-57 years and the lowest number $24(16 \%)$ of the respondents were found to age group 18-27 years. Mean age and Std. was $44.43 \pm 15.33$ years respectively. A study was conducted to estimate the prevalence of disability and its associated risk factors among adults aged 18 years and over in Bogra district, Bangladesh, it found that higher disability in higher age group with approximately eight-fold increase from $2.9 \%$ in 18-24 years to $24.5 \%$ in 55 years and above (Marella et al., 2010). Another study showed that the mean age and Std. was $40.8 \pm 14.1$ years (Groot $e t$ al., 2006). Previous study supports the finding of this study.

This study showed that highest $38(25.30 \%)$ reason of disability were stroke. Lowest $1(0.7 \%)$ reson of disability ware chronic disease. Fall from height, RTA and other reason of disbility ware 32 (21.39\%), 24 (16\%) and 12 $(8 \%)$ respectively. Another study showed in case of traumatic injury $18 \%$ are resulted of a road traffic accident (Hoque et al., 2002). The findings of previous study support the findings of this study.

This study found that out of 150 respondents, $67 \%$ had musculoskeletal disability, and $33 \%$ had neuro musculo disability. A study showed-Skeletal level of injury 39.2\% (Ditunno et al., 1997). According to CDA's statistics 2013 found Musculoskeletal/connective tissue disorders cause (28.5\%) disability and Cardiovascular/circulatory disorders cause (22.1\%) disability. Bangladesh Bureau of Statistics (2011) and Islam (2012) revealed that stroke was the third leading cause of death in Bangladesh and accounting for $2.55 \%$ of the total number of disabilities. Findings of previous and this study didn't show closer, that may be due to the problem of data collection technique.

In this study the inability of motor function of the respondents $(46.47 \%)$ was unable to walk stair, (46\%) unable to walk outdoor, $(24.70 \%)$ unable to take birth, rest $11.30 \%, 10.70 \%, 10 \%, 8 \%$ and $7.30 \%$ unable to- feed, get into bed, use wheelchair, use toilet and wear dress respectively. Physically impaired people have the largest share (about 31\%) among the PWDs. (Titumir and Hossain, 2005). A study found that ambulatory disability in the US working population was 5.3\% and West Virginia was $10.3 \%$. Self care disability in West Virginia were $3.2 \%$. Independent living disability was $6.6 \%$ in West Virginia. Findings of previous study support the finding of this study.

Among 150 respondents $16(10.7 \%)$ was lost their jobs due to disabilities. 1 of the respondents was uncertain and $133(88.7 \%)$ of the respondents didn't lose their job. A study showed that a job and family raise the quality of life of unemployed women with disabilities; these women should be given employment opportunities (primarily self-employment) as well as support for their families (Vuletic, 2007). Negative attitudes regarding people with disabilities as workers and employees are kept in place by myths by ineffective rehabilitation placement methods and by employer hiring procedures designed solely to avoid making risky hires.

Study found that highest $127(84.7 \%)$ of the respondents' community involvement was interrupted and lowest $23(15.3 \%)$ of the respondents' community involvement not interrupted. Deprived from visit of neighbor was $106(70.7 \%)$, uncertain $1(0.7 \%)$, no deprive from visit of neighbor was 43 (28.7\%). Deprived from visit of 
relatives and deprived from receive care of family was $70(46.7 \%)$ and $22(14.7 \%)$ respectively. Disability is something imposed on top of our impairments by the way we are unnecessarily isolated and excluded from society. People with disabilities regularly identify societal attitudes as the most potent and negative stressor in their lives.

Majority 13 (92.9\%) of the respondents among the severely disabled were found that their community involvement were interrupted, on the other hand $31(60.8 \%)$ of the respondents among the mildly disabled found that their community involvement were interrupted. This difference between physical disabilities and community involvement was found statistically significance. $(\chi 2=34.162, p=<0.05)$. Disable people can't move properly to attend the community or any social function. Thus social relation was found to be strongly associated with disease and disability.

\section{Conclusions and Recommendations}

This finding can be helpful to health professional especially those who are working with physical disabilities and make plan for development of disabled person. As a result effective intervention plan can reduce and prevent the cause of disability and provide appropriate rehabilitation of the disabled person.

The study forwarded following recommendation on the basis of the emerged findings:

i. Persons with physical disabilities have traditionally been perceived negatively and they were the burden in the family as well as society, despite the fact that the government can made public education and strengthened rehabilitation program.

ii. Physical disabilities hamper the psychosocial status of the disabled person. For improving the situation of the person with disabilities, actions should be taken to ensure their increased access to education, health and employment.

iii. Maximum causes of disability are preventable, effective awareness can prevent and reduce the rate of disability.

\section{Conflict of interest}

None to declare.

\section{References}

Altman B 2001. Disability Definitions, Models, Classification Schemes, and Applications. In Handbook of Disability Studies, ed. G. Albrecht, K. Seelman, and M. Bury. Sage Publications, pp. 97-122.

Bangladesh Bureau of Statistics. Population and housing census 2011, preliminary result. Dhaka: Bangladesh Bureau of Statistics; 2011. Accessed 2 Apr 2020. http://bbs.portal.gov.bd.

CDD, 2015. www.cdd.org.bd/aboutdisability/disabilityinformatin.

Ditunno JF, J Young, W Donovan, WH Maynard, FM Bracken, MB Creasey, G Ducker, TB Garber, SL Marino, RJ Stover, SL Tator, CH Waters and RL Wilberger, 1997. The international standards booklet for neurological and functional classification of spinal cord injury, American Spinal Injury Association. Paraplegia., 32:70-80.

Hoque MF, C Grangeon and K Reed, 2002. Center for the Rehabilitation of the Paralyzed, Bangladesh, viewed 17 Aug 2011, http://www.ncbi.nlm.nih.gov/ pubmed/10602529.

Islam MA, 2012. Cultural adaptation of COPCORD core English questionnaire and re-estimation of prevalence of rheumatic disorders in rural community of Bangladesh. MD Thesis, Bangabandhu Sheikh Mujib Medical University, Dhaka.

Marella M, L Nafisa, D Alexandra, M Sally, MA Baker and E Jill, 2015. Prevalence and correlation of disability in Bogra district of Bangladesh. BMC Public Health, 15: 867.

Titumir RAM and J Hossain, 2005. Disability in Bangladesh: Prevalence, Knowledge, Attitudes and Practices. In. Dhaka: Unnayan Onneshan.

UN Development Group, 2011. Including the rights of persons with disabilities, in United Nations programming at country level: A Guidance Note for United Nations Country Teams and Implementing Partners.

UK Disability Statistics, 2015. Office for Disability Issues published January 2014.

Vuletic MG, 2007. Relationship between depression and anxiety with a subjective assessment of quality of life, Speciality dissertation. Zagreb: Faculty of Philosophy in Zagreb.

WHO (World Health Organization), 2011. Disability and health, Retrieved 15-03-2012 at http://www.who.int/mediacentre/factsheets/fs352/en/.

World Health Organization and World Bank, 2011. World Report on Disability, p.28. http://www.who.int/disabilities/world_report/2011/en/index.html. 